\title{
Effect of lactose intolerance severity on food intake and quality of life in adults with lactose intolerance in Turkey
}

Effects of lactose intolerance severity

\author{
Gökçen Garipoğlu
}

Nutrition and Dietetics, Bahcesehir University, Istanbul, Turkey

Nesli Ersoy

Nutrition and Dietetics, Hacettepe Universitesi..Ankara, Turkey, and

Mustafa Gülşen and Taner Özgürtaş

Gülhane Training and Research Hospital, University of Health Sciences, Ankara, Turkey

\begin{abstract}
Purpose - Lactose intolerance is lactose digestive disorder due to lactase enzyme deficiency. This can affect the quality of life by restricting the intake of certain foods. The aim of this study is to show the lactose intolerance to the restriction in food intake and quality of life.

Design/methodology/approach - This study was conducted with adults aged 18-60 years. A survey was used to gather information on the demographic characteristics of the patients and their symptoms related to lactose intolerance. In addition, the Visual Analog Scale was administered to identify common symptoms and the World Health Organization Quality of Life (WHOQOL)-Bref Quality of Life Scale to determine their quality of life.

Findings - The average quality of life subscale scores was $56.25 \pm 14.06$ for physical, $58.29 \pm 11.72$ for mental, $63.28 \pm 21.35$ for social and $62.36 \pm 16.37$ for environmental. When VAS scores obtained for the common digestive system symptoms in lactose intolerance were compared with Quality of Life scores; it was found that physical life quality scores decreased $(r=-0.239, p=0.030)$ as the complaints of diarrhea increased and physical and environmental life quality decreased $(r=-0.316, p=0.004 / r=-0.277, p=0.012$, respectively) as abdominal pain increased.

Originality/value - People reduce dairy consumption due to digestive system complaints. Therefore, it is important to inform the people about the effects of lactose intolerance because discomfort caused by intolerance can affect nutrient intake and lower the quality of life.
\end{abstract}

Keywords Lactose, Lactose intolerance, Quality of life, Diet, Turkey

Paper type Research paper

\section{Introduction}

Lactose intolerance primarily develops due to an absence or shortage of lactase enzyme, and secondarily due to aging, inflammation of the small intestine, inflammatory diseases, human immunodeficiency virus (HIV) or malnutrition [1, 2]. The prevalence of lactase deficiency in Turkey has been reported to be $70 \%[3-5]$.

(C) Gökçen Garipoğlu, Nesli Ersoy, Mustafa Gülşen and Taner Özgürtaş. Published in Journal of Health Research. Published by Emerald Publishing Limited. This article is published under the Creative Commons Attribution (CC BY 4.0) licence. Anyone may reproduce, distribute, translate and create derivative works of this article (for both commercial and non-commercial purposes), subject to full attribution to the original publication and authors. The full terms of this licence may be seen at http:// creativecommons.org/licences/by/4.0/legalcode

Received 15 December 2020 
JHR

36,3

Nondigestible lactose in the small intestine leads to an increase in osmotic load in the colon, and consequently the passage of water into the intestine. Colonic flora ferments undigested lactose into the column, resulting in gases such as hydrogen $\left(\mathrm{H}_{2}\right)$, carbon dioxide and methane. Abdominal bloating, pain, diarrhea and constipation are observed in the presence of such gases [3]. Symptoms can be felt at different severity levels by affected individuals due to differences in the amount of lactose intake, intake of high lactosecontaining food with other nutrients, intestinal transition time and intestinal flora [6].

Lactose-containing milk and dairy products are the main source for dietary calcium, phosphorus, zinc and riboflavin, and milk proteins are also an important source of bioactive peptides [7]. Complaints after the consumption of such products result in a reduction or complete removal of milk and dairy products from the diet. This increases the risk of reduced bone mineral density, obesity, cardiovascular diseases and type 2 diabetes mellitus $[3,8]$.

Being selective in food consumption decisions and restricting dairy products in the diet may result in nutrition anxiety and increase the likelihood of nutrient deficiency, which in turn may affect quality of life [9]. It has been reported that the symptoms of lactose intolerance may increase the tendency to somatization, which may further impair quality of life [10]. The aim of this study was to evaluate the malabsorption symptoms of individuals with lactose intolerance and to investigate the effect of these symptoms on quality of life.

\section{Methods}

This study was conducted with adults aged 18-60 years who were referred from the gastroenterology department to the medical biochemistry department to undergo a lactose tolerance test the Gülhane Training and Research Hospital. During face-to-face interviews, a survey was used to gather information on the demographic characteristics and lactose intolerance symptoms of the patients, and the Visual Analog Scale (VAS) was administered to identify their common symptoms and the WHOQOL-Bref Quality of Life Scale [11, 12] to determine their quality of life. Patients with irritable bowel syndrome, inflammatory bowel diseases and celiac disease were excluded from the study.

Patients with lactose malabsorption complaints were referred by the gastroenterologist to the laboratory for a blood test. Abdominal pain, flatulence, gas, nausea, diarrhea and constipation after meals were considered as signs of malabsorption. For the diagnosis of lactose intolerance, first fasting blood glucose and then lactose loading $(50 \mathrm{~g} / 400 \mathrm{ml})$ blood glucose measurements were undertaken three times. Increases in blood glucose levels of $20 \mathrm{mg} / \mathrm{dL}$ or less compared to fasting levels were considered positive for lactose intolerance [13].

Using VAS, the participants were asked to score the severity of diarrhea, abdominal pain, nausea, bowel sounds, bloating and gas complaints from 0 to 10 , with 0 indicating no complaint and 10 representing to extremely severe complaints $[14,15]$. The WHOQOL Bref Quality of Life Scale consisting of the physical, mental, social and environmental subscales was also administered. This instrument is designed as a 5-point Likert scale, with each subscale being evaluated over 100 points. The closer the score is to 100 , the higher the quality of life. The validity and reliability study of the scale in Turkey was conducted by Eser et al. [16].

The study included individuals who were diagnosed with lactose intolerance for the first time and did not apply a lactose-restricted diet. Those that had a known metabolic disease and a history of antibiotic, probiotic or lactase enzyme use within the past two weeks were not included in the study. Informed consent was obtained from all the participants.

Descriptive statistics of the data were expressed as mean, standard deviation, number and percentages. Pearson's correlation test was used to evaluate the relationship between the 
quality of life and VAS scores. Statistical Package for the Social Sciences v. 20 was used for data analysis, and $p<0.05$ was considered as statistically significant.

\section{Ethical issue}

Ethics committee approval for the study was obtained from the Non-Interventional Research Ethics Committee of the hospital (Decision no: 18/234).

\section{Results}

A total of 144 lactose intolerant individuals (59 males and 85 females) aged 18-60 years participated in the study. The mean body mass index (BMI) of the participants was $23.9 \pm 15.5 \mathrm{~kg} / \mathrm{m}^{2}$ and their mean waist circumference measurement was $83.9 \pm 13.5 \mathrm{~cm}$ (Table 1).

After the consumption of milk and dairy products, intestinal gas (62.3\%) and stomach bloating (44.4\%) were most experienced by the participants. Of the participants, $14.9 \%$ stated that they completely eliminated any food that caused gas and bloating complaints and discomfort from their diet. They also reported that they consumed dairy products less frequently $(54.4 \%)$ and reduced their portion $(26.8 \%$ ) due to gastric complaints (Table 2).

\begin{tabular}{lr}
\hline Anthropometric measurements & $\bar{x} \pm \mathrm{SD}$ \\
\hline Body weight (kg) & $70.4 \pm 15.5$ \\
Height (cm) & $168.6 \pm 13.5$ \\
BMI (kg/m²) & $23.9 \pm 15.5$ \\
Waist circumference (cm) & $83.9 \pm 13.5$ \\
Note(s): SD: Standard deviation &
\end{tabular}

\section{Effects of lactose intolerance severity}

Table 1. Distribution of anthropometric measurements of individuals with lactose intolerance

\begin{tabular}{|c|c|c|}
\hline & $n$ & $\%$ \\
\hline \multicolumn{3}{|c|}{ Ailments reported after dairy consumption $(n=117)^{*}$} \\
\hline Gas & 73 & $62.3 \%$ \\
\hline Bloating in stomach & 52 & $44.4 \%$ \\
\hline Abdominal pain & 29 & $24.7 \%$ \\
\hline Diarrhea & 25 & $21.3 \%$ \\
\hline Heartburn & 25 & $21.3 \%$ \\
\hline Cramp in stomach & 10 & $8.5 \%$ \\
\hline Vomiting & 4 & $3.4 \%$ \\
\hline
\end{tabular}

Food consumption behaviors modified due to discomfort caused by milk consumption $(n=134)^{*}$

I try to consume it less often

I continue to consume it but reduce the amount of consumption

I have removed the product causing the symptom from my diet

I consume it by mixing it with other food products

$73 \quad 54.4 \%$

$36 \quad 26.8 \%$

$20 \quad 14.9 \%$

$1 \quad 1.34 \%$

Methods used to relieve discomfort after milk consumption $(n=137) *$

My discomfort resolves spontaneously

I am taking medication with my doctor's advice

$84 \quad 61.3 \%$

$26 \quad 18.9 \%$

As a precaution, I have reduced my milk consumption and I now use more fermented products, $\quad 11 \quad 8.0 \%$

such as yogurt, ayran, etc.

As a precaution, I constantly consume lactose-free milk

I discontinue drinking milk when I experience symptoms

$9 \quad 6.5 \%$

$7 \quad 5.1 \%$

Note(s): *Multiple answers could be given to all questions and some participants did not answer some of the questions
Table 2. Symptoms and behaviors related to the consumption of milk and dairy products 
JHR

36,3

\section{6}

Table 3.

Quality of life scale subscores of the individuals with lactose intolerance $\left(n=140^{*}\right)$
The mean values for the WHOQOL quality of life subscale scores of the participants were as follows: $56.25 \pm 14.06$ for the physical subscale, $58.29 \pm 11.72$ for the mental subscale, $63.28 \pm 21.35$ for the social subscale and $62.36 \pm 16.37$ for the environmental subscale (Table 3).

According to VAS scoring, the most common complaints of the participants were stomach bloating with an average score of $7.31 \pm 2.91$, followed by intestinal movements and gas with an average score of $6.03 \pm 3.17$ (Table 4).

When the VAS scores obtained for common digestive system symptoms in lactose intolerance were compared according to quality of life scores, it was found that the physical life quality scores decreased as the diarrhea complaints increased $(r=-0.239, p=0.030)$, and the physical and environmental life quality scores decreased as abdominal pain increased $(r=-0.316, p=0.004$ and $r=-0.277, p=0.012)$, and this resulted in a decrease in total quality of life $(p=0.027, p=0.005)$ (Table 5).

\section{Discussion}

Lactose intolerance is a health problem that causes symptoms such as abdominal pain, nausea, cramping, gas, diarrhea and vomiting after lactose consumption and results in a decrease in the quality of life of individuals [17]. It was observed that the most common complaints after the consumption of milk and dairy products were gas in the intestine, bloating in the stomach, abdominal pain, diarrhea and heartburn.

In a previous study, 580 individuals were evaluated in terms of lactose intolerance based on the symptoms they experienced, and $56 \%$ stated that they thought they were lactose intolerant. However, the rate of malabsorption was found to be $45 \%$ according to the $\mathrm{H}_{2}$ breath test results. It was determined that only half of the individuals with true lactose intolerance identified themselves as intolerant [9]. Similarly, there were participants in our study who stated that they had no complaints despite clear symptoms and thought that these symptoms were normal after dairy consumption. This indicates that the symptoms of lactose intolerance can be misinterpreted and some symptoms may be evaluated as part of a normal digestion process.

Lactose intolerance symptoms increase with an increasing consumption of lactose. It is suggested that the intake of lactose in diet should also be limited when receiving medical

\begin{tabular}{lc}
\hline Quality of life scale scores & $\bar{x} \pm \mathrm{SD}$ \\
\hline WHOQOL Physical Life Quality & $56,25 \pm 14.06$ \\
WHOQOL Mental Life Quality & $58.29 \pm 11.72$ \\
WHOQOL Social Life Quality & $63.28 \pm 21.35$ \\
WHOQOL Environmental Life Quality & $62.36 \pm 16.37$ \\
Note(s): SD: Standard deviation; *Four participants did not complete the WHOQOL scale & \\
\hline
\end{tabular}

Table 4.

Participants' VAS scores of discomfort experienced due to common symptoms in lactose intolerance $\left(n=83^{*}\right)$

\section{VAS scores}

How uncomfortable are you with diarrhea?

How uncomfortable are you with abdominal pain?

How uncomfortable are you with nausea?

How uncomfortable are you with intestinal movements and gas in intestines?

How uncomfortable are you with bloating in stomach?

Note(s): SD: Standard deviation; VAS: Visual Analog Scale; *Only 83 participants completed VAS

\section{$\bar{x} \pm \mathrm{SD}$}

$3.62 \pm 2.92$

$5.03 \pm 3.11$

$3.66 \pm 2.63$

$6.03 \pm 3.17$

$7.31 \pm 2.91$ 


\begin{tabular}{|c|c|c|c|c|c|c|c|}
\hline & & $\begin{array}{l}\text { Physical } \\
\text { life quality }\end{array}$ & $\begin{array}{l}\text { Mental } \\
\text { life } \\
\text { quality }\end{array}$ & $\begin{array}{l}\text { Social } \\
\text { life } \\
\text { quality }\end{array}$ & $\begin{array}{c}\text { Environmental } \\
\text { life quality }\end{array}$ & $\begin{array}{c}\text { Total life } \\
\text { quality }\end{array}$ & $\begin{array}{r}\text { Effects of } \\
\text { lactose } \\
\text { intolerance }\end{array}$ \\
\hline VAS "How uncomfortable are & $r$ & $-0.239^{*}$ & -0.175 & -0.087 & -0.182 & $-0.244^{*}$ & severity \\
\hline you with diarrhea?” & $p$ & 0.030 & 0.116 & 0.439 & 0.102 & 0.027 & \\
\hline VAS "How uncomfortable are & $r$ & $-0.316^{* *}$ & -0.199 & 0.010 & $-0.277^{*}$ & $-0.308^{* *}$ & \\
\hline you with abdominal pain?" & $p$ & 0.004 & 0.073 & 0.926 & 0.012 & 0.005 & 537 \\
\hline VAS "How uncomfortable are & $r$ & -0.163 & -0.156 & -0.108 & -0.211 & -0.208 & \\
\hline you with nausea?” & $p$ & 0.142 & 0.161 & 0.334 & 0.057 & 0.061 & \\
\hline VAS "How uncomfortable are & $r$ & $-0.296^{* *}$ & -0.107 & -0.046 & -0.075 & -0.204 & \\
\hline $\begin{array}{l}\text { you with intestinal } \\
\text { movements and gas in } \\
\text { intestines?" }\end{array}$ & $p$ & 0.007 & 0.337 & 0.680 & 0.503 & 0.067 & \\
\hline VAS "How uncomfortable are & $r$ & $-0.234^{*}$ & -0.038 & -0.089 & -0.072 & -0.170 & $\begin{array}{r}\text { Table } 5 \text {. } \\
\text { Relationship betwen }\end{array}$ \\
\hline you with bloating in stomach?" & $p$ & 0.034 & 0.732 & 0.426 & 0.519 & 0.127 & quality of life and VAS \\
\hline \multicolumn{8}{|c|}{ Note(s): SD: Standard deviation; VAS: Visual Analog Scale Pearson's correlation test, $* p<0.05, * * p<0.001$} \\
\hline
\end{tabular}

treatment for this condition. In adults, the tolerance of $12 \mathrm{~g}$ of lactose from about 1 cup of milk does not usually cause any problems, and symptoms usually emerge when the dose is increased to $18 \mathrm{~g}$ or above [18]. In our study, the participants reported that in order to relieve their symptoms, they completely removed any food product $(14.9 \%)$ that caused gas and bloating complaints and discomfort from their diet, consumed dairy products less frequently $(54.4 \%)$ or reduced the portion $(26.8 \%)$. In a similar study which indicated that $41 \%$ of individuals with lactose intolerance limited the consumption of dairy products, $31 \%$ of nonintolerant individuals reported to avoid dairy products [9]. With the removal of milk and dairy products from the diet, nutrient intake becomes limited, and there may be deficiencies related to the reduced intake of phosphorus, riboflavin and especially calcium [18]. In addition to an insufficient intake of calcium, it has been reported that lactose may increase the severity of calcium deficiency and could pose a risk for bone health because it helps the absorption of calcium in the intestines [19]. Another hypothesis is that the consumption of milk and dairy products decreases blood pressure, has a positive effect on cardiac and vascular muscle contraction, and also reduces the development of colon cancer-related adenomas. It has been reported that short-chain fatty acids such as butyrate, which result from the fermentation of lactic acid bacteria, have mucosal growth and inflammation-reducing effects [20]. For this reason, it should be determined whether individuals with lactose intolerance obtain sufficient calcium through their diet, and nutrients that are likely to be deficient should be supported with other dietary sources. In addition, unnecessary restraints should be taken into consideration as digestive system complaints may not always be caused by lactose. In a study of 323 people aged five to 85 years in Sicily, it was shown that calcium intake was $230-585 \mathrm{mg} /$ day in patients, people without lactose intolerance also restrict milk and dairy products due to intolerance-like symptoms. This amount is below the recommended daily values (800-1,200 mg/day) [21]. Similarly, it is recommended to consume dairy products with reduced lactose in order to maintain nutrient intake, especially for bone health. However, lactase enzyme tablets are also recommended to reduce symptoms after dairy consumption $[22,23]$. Although most of the participants in our study expected their complaints to disappear spontaneously after milk consumption, $18.9 \%$ used drugs to reduce their symptoms and $14.5 \%$ preferred products with reduced lactose.

Chronic diseases often cause a decrease in the quality of life of patients. Lactose intolerance is one of the most common malabsorption conditions, and a limited number of studies have shown that it may cause a decrease in quality of life due to symptoms 
JHR

36,3 experienced [9, 17, 21]. The participants in our study scored between $56.25 \pm 14.06$ and $63.28 \pm 21.35$ in the WHOQOL Quality of Life Scale. Thus, the quality of life of the participants can be evaluated as moderate. However, in a study in which 265 people with lactose intolerance were compared with 315 without intolerance, the total quality of life score was found to be 60 in intolerant subjects and 70 in tolerant subjects [9]. In our study, the participants having a high rate of milk product restriction may have had an effect on the results since they experienced fewer symptoms.

According to the VAS scores (1 to 10 points) assigned by the participants to each of the common digestive system symptom associated with lactose intolerance, they mostly suffered from bloatedness with an average score of $7.31 \pm 2.91$, intestinal movements and gas with an average score of $6.03 \pm 3.17$, and abdominal pain with an average score of $5.03 \pm 3.11$. Similarly, in a study conducted by Casellas et al. [9], it was reported that the highest rate of discomfort was caused by intestinal sounds, gas and abdominal pain according to the VAS assessments. In both studies, the complaints of discomfort due to diarrhea were low. This can be explained by the participants' reduced milk consumption.

In a study showing the differences between the perception of symptoms of lactose intolerance in daily life and the symptoms observed after the lactose loading test, it was reported that individuals tended to exaggerate the symptoms they experienced in daily life [24]. In our study, when the relation between the VAS and quality of life scores was investigated, it was seen that the diarrhea and abdominal pain complaints decreased the physical life quality and total quality of life scores $(p=0.027$ and $p=0.005)$. It was observed that the physical activity quality decreased as the intestinal movements and gas complaints and bloating complaints increased $(r=-0.296, p=0.007$ and $r=-0.234, p=0.034)$, but the effect of these complaints on the total quality of life was not statistically significant $(\phi=0.127)$. Similarly, in a study evaluating patients with celiac disease, it was reported that quality of life increased with the absence/decrease of gastrointestinal symptoms [25]. The symptoms of the digestive system causing a decrease in quality of life may result from both pain and discomfort related to bloating or it may also be due to inadequate vitamin and mineral intake.

It is important to inform patients about the effects of lactose intolerance on quality of life considering the prevalence of lactose intolerance in community. People should also be informed about other diseases (osteoporosis, hypertension, etc.) that may result from unnecessary nutritional restriction. In addition, increasing the diversity of lactose-free and lactose-reduced products available in the food industry can positively contribute to the quality of life of those with lactose intolerance.

\section{Specificity and limitations of the study}

In Turkey, the number of studies conducted with lactose intolerant individuals is very limited, and there is no research concerning the effect of this condition on quality of life. In this respect, our study is one of the first in the literature. The reason for the limited number of participants is the lack of reimbursement for lactose tolerance testing in the Health Implementation Regulations of the Turkish Social Security Institution and only one center undertaking invasive blood sampling and conducting the study. The number of participants could be increased by increasing the number of centers and conducting the lactose tolerance test with more practical and inexpensive methods such as the hydrogen respiration test instead of blood sampling, and thus more detailed and valuable studies can be performed. Since this is an invasive test, the number of people who volunteer to enroll in a control group is also insufficient. Lactose intolerance was detected in 30 of 35 patients who were invited to the control group and had no complaints. These people reported to have no complaints because they thought what they experienced was normal even though 
there were signs of malabsorption. Therefore, in this study, a control group could not be formed.

Conflict of Interest: None

\section{Effects of lactose intolerance severity}

\section{References}

1. Rosado JL. Lactose intolerance. Gac Med Mex. 2016; 152(Suppl 1): 67-73. (in Spanish).

2. Mahan LK, Raymond JL. Krause's food and the nutrition care process. 14th ed. St. Louis, MO: Saunders; 2016.

3. Yilmaz Köse B, Ölmez Y. Lactose intolerance and diet. Güncel Gastroenteroloji. 2016; 20(3): 245-52. (in Turkish).

4. Flatz G, Henze HJ, Palabiyikoglu E, Dagalp K, Turkkan T. Distribution of the adult lactase phenotypes in Turkey. Trop Geogr Med. 1986; 38(3): 255-8.

5. Tuncbilek E, Türün R, Say B. Lactose intolerance in Turkey. Lancet. 1973; 2(7821): 151.

6. Zhao J, Fox M, Cong Y, Chu H, Shang Y, Fried M, et al. Lactose intolerance in patients with chronic functional diarrhoea: the role of small intestinal bacterial overgrowth. Aliment Pharmacol Ther. 2010; 31(8): 892-900. doi: 10.1111/j.1365-2036.2010.04252.x.

7. Corgneau M, Scher J, Ritie-Pertusa L, Le DTL, Petit J, Nikolova Y, et al. Recent advances on lactose intolerance: tolerance thresholds and currently available answers. Crit Rev Food Sci Nutr. 2017; 57(15): 3344-56. doi: 10.1080/10408398.2015.1123671.

8. Saltzman JR, Russell RM, Golner B, Barakat S, Dallal GE, Goldin BR. A randomized trial of Lactobacillus acidophilus BG2FO4 to treat lactose intolerance. Am J Clin Nutr. 1999; 69(1): 140-6. doi: 10.1093/ajcn/69.1.140.

9. Casellas F, Aparici A, Perez MJ, Rodriguez P. Perception of lactose intolerance impairs healthrelated quality of life. Eur J Clin Nutr. 2016; 70(9): 1068-72. doi: 10.1038/ejcn.2016.80.

10. Zheng X, Chu H, Cong Y, Deng Y, Long Y, Zhu Y, et al. Self-reported lactose intolerance in clinic patients with functional gastrointestinal symptoms: prevalence, risk factors, and impact on food choices. Neurogastroenterol Motil. 2015; 27(8): 1138-46. doi: 10.1111/nmo.12602.

11. The WHOQOL Group. Development of the world health organization WHOQOL-BREF quality of life assessment. Psychol Med. 1998; 28(3): 551-8. doi: 10.1017/s0033291798006667.

12. Skevington SM, McCrate FM. Expecting a good quality of life in health: assessing people with diverse diseases and conditions using the WHOQOL-BREF. Health Expect. 2012; 15(1): 49-62. doi: 10.1111/j.1369-7625.2010.00650.x.

13. Briet F, Pochart P, Marteau P, Flourie B, Arrigoni E, Rambaud JC. Improved clinical tolerance to chronic lactose ingestion in subjects with lactose intolerance: a placebo effect?. Gut. 1997; 41(5): 632-5. doi: 10.1136/gut.41.5.632.

14. Casellas F, Varela E, Aparici A, Casaus M, Rodriguez P. Development, validation, and applicability of a symptoms questionnaire for lactose malabsorption screening. Dig Dis Sci. 2009; 54(5): 1059-65. doi: 10.1007/s10620-008-0443-3.

15. Aydin A, Araz A, Asan A. Visual analog scale and affect grid: an application to Turkish culture. Türk Psikoloji Yazılar. 2011; 14(27): 1-13. (in Turkish).

16. Eser E, Fidnner H, Fidaner C, Eser SY, Elbi H, Göker E. Psychometric properties of the WHOQOL$10 O$ and WHOQOL-BREF. Psikiyatri Psikoloji Psikofarmakoloji Dergisi. 1999; 7(Suppl 2): 23-40. (in Turkish).

17. Vandenplas Y. Lactose intolerance. Asia Pac J Clin Nutr. 2015; 24(Suppl 1): S9-13. doi: 10.6133/ apjcn.2015.24.s1.02.

18. Brown-Esters O, Mc Namara P, Savaiano D. Dietary and biological factors influencing lactose intolerance. Int Dairy J. 2012; 22(2): 98-103. doi: 10.1016/j.idairyj.2011.09.010. 
JHR

36,3

540
19. Fina BL, Brun LR, Rigalli A. Increase of calcium and reduction of lactose concentration in milk by treatment with kefir grains and eggshell. Int J Food Sci Nutr. 2016; 67(2): 133-40. doi: 10.3109/ 09637486.2015.1137888.

20. NIH Consensus Development Conference: Lactose intolerance and health, 22-24 February 2010, Bethesda, Maryland. [cited 2019 August 26]. Available from: https://consensus.nih.gov/2010/ lactosestatement.htm.

21. Carroccio A, Montalto G, Cavera G, Notarbatolo A. Lactose intolerance and self-reported milk intolerance: relationship with lactose maldigestion and nutrient intake. Lactase Deficiency Study Group. J Am Coll Nutr. 1998; 17(6): 631-6. doi: 10.1080/07315724.1998.10718813.

22. Ibba I, Gilli A, Boi MF, Usai P. Effects of exogenous lactase administration on hydrogen breath excretion and intestinal symptoms in patients presenting lactose malabsorption and intolerance. Biomed Res Int. 2014; 2014: 680196. doi: 10.1155/2014/680196.

23. Szilagyi A, Ishayek N. Lactose Intolerance, dairy avoidance, and treatment options. Nutrients. 2018; 10(12): 1994. doi: 10.3390/nu10121994.

24. Casellas F, Aparici A, Casaus M, Rodríguez P, Malagelada JR. Subjective perception of lactose intolerance does not always indicate lactose malabsorption. Clin Gastroenterol Hepatol. 2010; 8(7): 581-6. doi: 10.1016/j.cgh.2010.03.027.

25. Mager DR, Marcon M, Brill H, Liu A, Radmanovich K, Mileski H, et al. Adherence to the glutenfree diet and health-related quality of life in an ethnically diverse pediatric population with celiac disease. J Pediatr Gastroenterol Nutr. 2018; 66(6): 941-8. doi: 10.1097/mpg.0000000000001873.

\section{Corresponding author}

Gökçen Garipoğlu can be contacted at: gokcen.garipoglu@hes.bau.edu.tr

For instructions on how to order reprints of this article, please visit our website: 